\title{
THE ECONOMIC ASPECT OF A WORKING PLAN ON AN EXPERIMENTAL FOREST
}

\author{
By R. H. Candy \\ Dominion Forest Service
}

$\mathrm{T}^{\mathrm{H}}$ HE preparation of a working plan in any Canadian forest is a rarity; the application of a working plan on any Canadian forest is, until very recent years, unknown. In the last few years, some of the large pulp and paper companies have made a determined effort to prepare and follow out a working plan in a broad manner. The plans, however, generally apply to balsam and spruce, and not to the many species that constitute a forest. The problem of improving the productive capacity of a forest is quite unsolved and a source of concern to the forestry profession to-day.

An effort to solve some of the difficulties that occur in carrying out a working plan in our forests should be studied in our areas set aside for experimental purposes, such as exists at Petawawa.

Practically speaking, then, we are confronted with two facts: first, that in Europe, working plans are in general and successful use, and second, that in Canada they are not. There is a reason for this, viz., economics. Is it not probable that the methods of forest utilization in Canada are so specialized and so unstable as to create a condition entirely foreign to a definite plan?

The preparation of a working plan that will consider all species in a forest, and that will consider the general good of a forest as a whole, would, one might feel, need a great deal of courage. How much more courage, therefore, is needed to prepare a working plan on a forest which must be employed for experimental purposes! Such a plan is being prepared for the Petawawa forest experiment station, and will be in full operation this year. It is this station that I am about to discuss, where we have studied the economic aspect preparatory to the adoption of the working plan.

The Petawawa forest experiment station is known to, and has been visited by many of you present at this meeting, but to those who have never visited it, it can be roughly described as an area representing typical cut-over lands of eastern Ontario, logged for pine 50 years ago when these operators swept up the Ottawa Valley. That these operations were followed by fires can be taken for granted. This experimental area is therefore covered by young stands of timber of many types and many species between 20 and 70 years of age. Only $6 \%$ of the timber is over 70 years of age. There is nothing exceptional about the timber on this area; it is typical of cut-over lands in most of Ontario, and possibly Quebec.

The main difficulty encountered in any working plan in Canada, where the growth of all species is concerned, is not so much arriving at an amount 
that should be cut annually, but to find some economic use for it-in other words, the difficulty lies in disposing of the timber that the plan dictates should be cut. In Europe this difficulty does not present itself. They have found the solution,-it is to develop a steady market for all the species and all the classes of timber that a forest can produce.

When I say that at Petawawa, taking advantage of wood-using industries, we have attempted to bring about a situation similar to Europe, you will feel that we have attempted a difficult task. When I state that in addition to this, we require operators to practise brush disposal and to cut the timber in the special manner that a particular experiment demands, you would really feel that our efforts were likely to meet insurmountable difficulties. That these difficulties at Petawawa have not proved insurmountable, and the manner in which we have attempted to overcome them, I will now attempt to explain. first.

Let us first take our problems one by one, and the smallest problems

On the Petawawa experiment station, it is necessary that all coniferous brush be burned, and hardwood brush scattered by the operator. At first we encountered every difficulty, and every attempt was made to get around it; but we were firm, and there is no ease on record where brush was not eventually disposed of at the operator's cost. To-day we have no difficulty; local operators are accustomed to it, and have learned to do it cheaply. To say the problem had disappeared except for its supervision would sound unreasonable, but this is practically the case. It is now one of the least of our troubles....

To cut the timber in a manner to meet requirements of an experiment also met with opposition. Operators did not like being barred from cutting in areas held in reserve for control plots, or cutting only trees marked for cutting, but they soon became accustomed to it, and opposition dies down much more quickly than one might expect. This is another problem which does not bother us to-day, and just needs careful supervision.

We now come to the greatest problem of all-the disposal of all classes of material called for under a working plan; not the disposal of pine, spruce and balsam, but also of poplar, maple, birch, basswood and the numerous other hardwoods in our forest at Petawawa. We are able to do this at Petawawa; we are doing it now when the forest industries are in the worst state of depression, and our prospects of extending the utilization of all species in the future are bright.

This economic aspect of a working plan can only be brought into proper relations by effort-an effort to utilize as much as possible the industries available in the district; an effort to meet the directors of these industries, point out the advantages of having a well-managed forest in their vicinity, 
and obtain their support and co-operation;-an effort to try and develop and encourage the sale of fuelwood;-and, what is even more important, employ the type of operator in the forest who is most likely to meet your needs and who most easily dovetails into your organization.

I will now attempt to show what efforts we have made to overcome our own problems, and with what success.

There are in the Town of Pembroke, lumber mills, a box factory and a match plant. These are our advantages which we try to cultivate. The superintendent often visits the manager of some of these industries and discusses our plans, points out our attempt to provide a constant supply, why we burn brush, why we make experimental cuttings. Managers, like other people, are curious, and are far more sympathetic to our endeavours than was ever expected. In fact it can be said quite definitely that the co-operation and interest obtained from hard-boiled managers has been one of the greatest surprises and encouragement in the Superintendent's experience as a forester, and he could give many instances where these industries have been the greatest help to us. Managers of a permanent industry can, of course, see the value of a forest where they know that so much timber can be obtained each year, where the cost is known, the haul more or less known, and conditions governing sales consistent. It tends towards a stable estimate of expense.

Another problem we have had to face is the disposal of thinnings-the removal of weed trees or hardwoods suppressing conifers. We therefore studied the problem of fuelwood, and made an effort to interest people to dispose of fuelwood in Pembroke, more or less as an experiment, and to our great surprise, it turned out such a success that several hundred cords will be sent to Pembroke this winter; and from interviews had with operators, they plan to take large amounts next season. Laundries, schools and minor plants annually contract for large quantities of fuelwood. We might have taken the attitude that since fuelwood had never been shipped to Pembroke from the experimental area, a distance of about 18 miles, it could not be done; but it is being done now, even with the price at its lowest, and economic conditions at their worst.

Now we come to the most important point of all-it might be called the key to success-namely, the type of operator who is most likely to meet your needs and who most easily dovetails into your organization. The answer is the small operator-the smaller the better. A small operator will take out small quantities of timber, 25, 50, 100 to 500 cords of wood. He has a small overhead expense and can afford to operate anywhere. He is invariably a local inhabitant who knows the country, knows us, and comes back for more year after year. He will take out the small pockets of timber, which are typical of an ever-changing, mosaic of types in forests repeatedly cut and 
burned over in the past; and, what is vital to us, a small operator will handle timber marked by us on a small area for any one of our many experiments. .... A large operator cannot pay attention to the small groups of timber, and they do not cut as cleanly. For example, two small operators removed 100 cords of poplar from less than ten per cent of an area cut over the previous year by a larger operator when the same species was removed.

The larger the operator, the harder he is to supervise and deal with, for a variety of obvious reasons; in addition, a large operator must build a set of camps, employ foremen, clerks, cooks, and become involved in a lot of overhead. A small operator and his men will either use a tent or build a small shack, do their own cooking, and rarely comprises more than four men and a team. On an experimental area as at Petawawa, it can easily be arranged to have one small operator cut timber under one system, and another operator cut under a different system. For one large operator to work under two or three different systems produces too much confusion . . . . For purposes of definition, we would consider a man who cut over 1000 cords a large operator.

Our means of disposing of timber is carried out under two systems:

1. By public auction, when the conditions of the sale are advertised;

2. The permit system, when dues are set and conditions laid down in the contract.

The following example will illustrate how one of the public auction sales operates. An area was selected by us to be used for the purpose of conducting experiments in the reproduction of white spruce. The area had previously been cut over for poplar, and there remained a mixedwood stand con taining balsam, maple, yellow and white birch, basswood, ash, a little poplar, and a scattering of spruce and hemlock. The stand was uneven-aged. It also contained a large number of over-mature defective hardwoods of no com. mercial value that had to be removed if the experiment was to be a success.

All trees to be removed were marked by us, and the stand put up for public auction. The operator had to cut balsam, poplar, yellow and white birch, maple, ash and basswood, but no spruce, pine or hemlock. He also had to cut down the over-mature defective trees, from which he could get no lumber. He had to scatter all hardwood brush and burn the balsam brush. This operation was successfully carried out; we obtained an average price of $\$ 4.90$ per thousand for it; and we established three excellent sample plots for experimental purposes. This is rather an extreme case, presenting many difficulties,but it illustrates what can be done if an effort is made. . . It might be observed by a person being shown over the experimental cutting, that of course any condition can be artificially created provided sufficient money is spent on the operation; but to be able to show that the conditions were not created at our expense,- that it was an economic operation producing a fair revenue,-adds value, but more important, prestige to our experiments. 
With regard to the permit system, any person can obtain a contract providing the timber in question is for sale, and he pays his whole dues before permit to cut is granted. Permits are issued up to 100 cords, a second permit being issued if necessary. No man can obtain a single permit exceeding 100 cords at a time. This permit system, which is most used on the Petawawa research station, has the most advantages to us in carrying out experiments, and is the easiest to administer. It is the most popular with the local operators, and is the system which at present we feel most inclined to encourage An area is opened up for sale, under the working plan, and the timber permits are issued to applicants to cut timber in that area, each operator being confined to part of the area to prevent confusion. Generally speaking, the first applicant has first choice of site ....

An example will prove in this instance the working out of an experiment, the operations to be done under the permit system. We have an area about 12 miles from the mouth of the Petawawa river where poplar is to be removed to release a coniferous advance growth. This area, under the working plan, is already marked for removal. It would be convenient to remove this poplar under the permit system in order that some operators can follow one system of cutting, and some another. An interview we had recently with one of the industries in Pembroke revealed that that concern would take about 3000 cords of this poplar, and would give small contracts to the local inhabitants, and the company would themselves drive the whole amount down the Petawawa river. . . This same company carried out the procedure of letting out small contracts during the present winter. A point to be brought out at this moment is the remarkable way that we are able to obtain co-operation by the industries, and a large part of the success that we may enjoy should be credited to them.

To date this year, we have issued over 40 permits to operators, and four trucks are drawing logs day and night, besides several sleighs. The average haul is about 16 to 18 miles. In fact we have been obliged to refuse applications for timber because our plans for experiments were not ready.

It has been pointed out that the great difficulty of carrying out a proper working plan in Canada is the economic aspect. In spite of the depression in the forest industry, we have had sufficient indications of success to feel that we are on the road to overcome this difficulty. We feel that we have the advantage that the ball once moved can be kept rolling with much less effort than the initial "big push." We have instances of that already. A road built to cut out poplar will be used to cut out fuelwood, and then will be extended to cut more poplar or more fuelwood. To illustrate this point, we have an area in the centre of the reserve where we never would have hoped to dispose of fuelwood at this time. However, we sold 100 cords of 
poplar, and, because the road to this poplar was already cut, a man has just applied for and been granted a permit to cut 150 cords of fuelwood in this area, under two permits. In addition, two small mills have recently established themselves on the boundary of the experiment station.

The economic aspects of a working plan on an experimental area must, on account of the many conditions that the word "experiment" implies, present far greater difficulties than for a working plan of any other area; and if these difficulties can, even in part, be overcome, as they appear to be at the Petawawa forest experiment station, surely there must be some hope in other areas where the requirements of research do not complicate matters, if an organized effort were only made. It is admitted that at Petawawa we have the help of diversified industries, but surely there are many similar conditions in other parts of Canada.

It is to be hoped that the success of our efforts on our experiment station at Petawawa will help to provide that hope and that encouragement which are so needed at the present time.

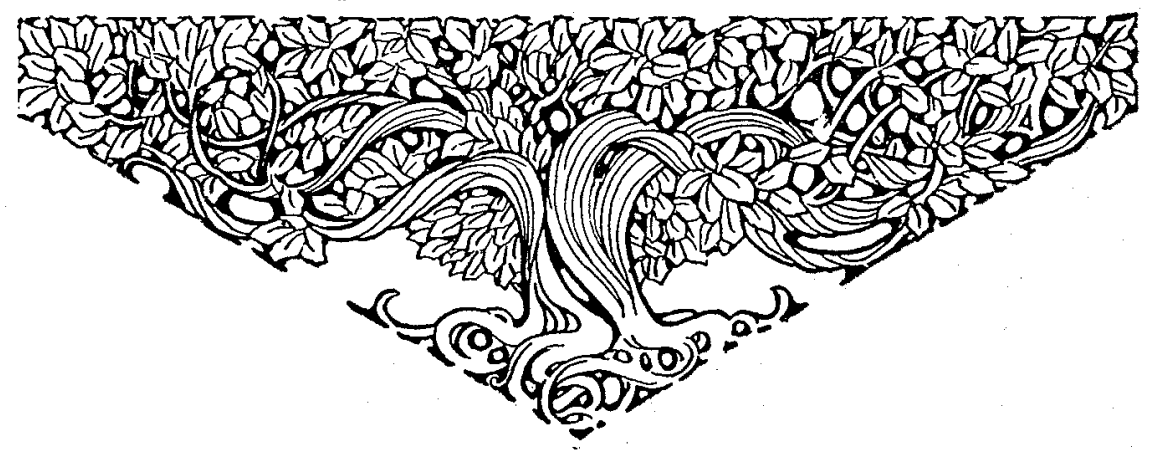

